\title{
Educação financeira por meio de dados reais: atividades didáticas para a educação básica
}

\section{Ana Carolina Gadotti} gadotti.ana@gmail.com 0000-0002-9342-1693

Universidade Regional de Blumenau

(Programa de Pós-Graduação em Ensino de Ciências Naturais e Matemática),

Brasil.

\section{Tânia Baier}

taniabaier@gmail.com

Universidade Regional de Blumenau

(Programa de Pós-Graduacão em Ensino de Ciências Naturais e Matemática),

Brasil.

\section{RESUMO}

Este trabalho apresenta parte de uma pesquisa desenvolvida no Programa de PósGraduação em Ensino de Ciências Naturais e Matemática da Universidade Regional de Blumenau. O objetivo deste trabalho é elaborar e aplicar atividades didáticas para a educação básica sobre o tema Educação Financeira fundamentadas em dados reais, colaborando para preparar os estudantes para o consumo sustentável e para uma vida financeira responsável. Os sujeitos da pesquisa foram 26 estudantes de uma turma dos anos finais do ensino fundamental de uma escola localizada na cidade de Blumenau-SC. A Educação Financeira pode contribuir no processo da construção da cidadania, colaborando para tornar o estudante mais autônomo e preparado para tomar melhores decisões no campo econômico e financeiro. Neste trabalho são descritas duas atividades desenvolvidas com os estudantes durante as aulas de Matemática.

PALAVRAS-CHAVE: Educação financeira. Ensino fundamental. Atividades. 


\section{INTRODUÇÃO}

Através das mídias, seja na TV, no jornal ou na internet, sabe-se que questões ligadas a economia estão sempre em alta, principalmente quando destacam-se assuntos relacionados ao endividamento das famílias e crises financeiras. Nos dias de hoje comprar algo do nosso interesse mesmo sem ter dinheiro tornou-se algo mais fácil com a opção de crediário, porém, o uso incontrolável e inconsciente do cartão crédito tem tornado muitas pessoas consumistas e endividadas. Estabelecimentos comerciais vendem mercadorias a prazo e, como o valor mensal é pequeno, as massas populares tendem a adquirir mais objetos.

Com a Educação Financeira as pessoas podem aprender a cuidar do seu dinheiro e dos seus investimentos. Informações estatísticas, cálculos matemáticos e planilhas auxiliam nesse controle de administrar os ganhos e gastos. Pelicioli (2011) destaca que as pessoas estão sempre envolvidas com finanças, seja no ambiente escolar, familiar ou profissional e que, os conhecimentos acerca de consumo, economia, dívidas e juros apresentam-se na vida de forma prática. $\mathrm{O}$ autor também ressalta que, no Brasil, infelizmente, a Educação Financeira não é parte do universo educacional familiar e, tampouco, escolar.

Se todos os estudantes tivessem a oportunidade de aprender sobre Educação Financeira nas escolas, a formação do cidadão crítico poderia acontecer, colaborando para todos terem consumos e uma vida financeira conscientes. A Educação Financeira nas escolas também pode ajudar no processo da construção da cidadania, colaborando para o desenvolvimento de um estudante mais autônomo e preparado para tomar melhores decisões no campo econômico e financeiro. "Todo ser humano deve ser preparado, especialmente graças à educação que recebe na juventude, para elaborar pensamentos autônomos e críticos e para formular os seus próprios juízos de valor, de modo a poder decidir, por si mesmo, como agir nas diferentes circunstâncias da vida" (DELORS, 2000, p. 99).

Este trabalho tem por objetivo apresentar a análise de algumas atividades desenvolvidas com uma turma das séries finais do ensino fundamental, em uma pesquisa desenvolvida no Programa de Pós-Graduação em Ensino de Ciências Naturais e Matemática (Mestrado Profissional) da Universidade Regional de Blumenau (PPGECIM/FURB).

\section{A IMPORTÂNCIA DA EDUCAÇÃO FINANCEIRA}

Segundo uma pesquisa realizada pelo Serviço de Proteção ao Crédito (SPC Brasil) e pela Confederação Nacional de Dirigentes Lojistas (CNDL) com 600 pessoas de ambos os sexos e acima de 18 anos de idade, de todas as regiões brasileiras e de todas as classes sociais, a principal meta da população brasileira para o ano de 2016 é "sair do vermelho", sendo que $36,8 \%$ dos consumidores desejam pagar suas contas atrasadas. Nessa mesma pesquisa constataram que o cartão de crédito foi o principal motivo da inadimplência no ano de 2015 (SPC Brasil, 2016). acima de 18 anos de idade nas 27 capitais, aponta que 36,3\% dos consumidores 
fazem compras para aliviar o estresse e que, comprar, mesmo sem planejar antes, é o lazer predileto para três em cada dez entrevistados. Entre os 745 consumidores entrevistados, $24,5 \%$ confessam realizar compras quando se sentem deprimidos. $\mathrm{O}$ apelo ao consumo pode ser tão forte que grande parte dos consumidores esquecem os efeitos que essa compra sem planejamento pode afetar o seu orçamento, onde $30,7 \%$ admitem que, quando veem um produto atrativo, não pensam nas consequências da compra antes de efetivá-la (SPC Brasil, 2016).

O consumismo é um problema que afeta muitas pessoas e famílias, levandoas, muitas vezes, a se endividar cada dia mais. Nos dias de hoje estamos cercados por propagandas que instigam as pessoas a comprarem compulsivamente, sendo que as crianças e os adolescentes estão crescendo e sendo incentivados a serem consumistas. Nesse contexto, conteúdos relacionados a Educação Financeira devem ser implementados nas aulas de Matemática não somente nos anos finais do ensino fundamental, mas sim, desde os anos iniciais da educação básica.

Para Savoia, Saito e Santana (2007) a Educação Financeira pode ser entendida como um processo de transmissão de conhecimento que permite que as pessoas desenvolvam habilidades para que elas possam tomar decisões seguras e melhorar o gerenciamento de suas finanças pessoais. Para os autores, quando as pessoas aprimoram essas capacidades, acabam se tornando indivíduos mais integrados à sociedade e também mais atuantes no âmbito financeiro, ampliando assim o seu bem-estar. Os autores também destacam que:

\footnotetext{
Mudanças tecnológicas, regulatórias e econômicas elevaram a complexidade dos serviços financeiros. Mas a insuficiência de conhecimento sobre o assunto, por parte da população, compromete as decisões financeiras cotidianas dos indivíduos e das famílias, produzindo resultados inferiores ao desejado. (SAVOIA; SAITO; SANTANA, 2007, p. 1122)
}

Campos (2012) destaca que as pessoas têm à sua frente desde a infância muitos bens e serviços disponíveis, e que o apelo do marketing está cada vez maior. "Jovens egressos da Educação Básica terão, no dia a dia, necessidade de administrar seus orçamentos tomando decisões em relação ao uso do próprio dinheiro" (CAMPOS, 2007, p. 39). Domingos (2011) relata que pesquisas apontando o fato da maioria das pessoas que ficam milionárias sem imaginar de um dia para o outro, em pouco tempo, voltam a ser pobres. $O$ autor questiona: Por que isso acontece? E responde: essas pessoas não sabem gerir o dinheiro. $O$ autor também defende a ideia que, não importa quanto dinheiro a pessoa possui, mas sim como ela administra o que tem.

Desde 1998, os Parâmetros Curriculares Nacionais (PCN) de Matemática para o terceiro e quarto ciclos do ensino fundamental tem apontado que pesquisas realizadas sobre os temas trabalho e consumo podem fornecer contextos para que os conceitos e os procedimentos estatísticos ganhem significado. O documento também apresenta que trabalhar situações que envolvam Matemática Comercial e Financeira auxiliam os estudantes a compreender, decidir e avaliar diversas situações cotidianas, como por exemplo a melhor forma de pagar uma compra ou escolher um financiamento. Seguindo as recomendações dos PCN, podem ser acessadas informações sobre consumo e endividamento da população brasileira por meio da utilização de laboratórios de informática, disponíveis na maioria das escolas. Atualmente, a versão em discussão da Base Nacional Comum Curricular estabelecer a integração entre os componentes curriculares de uma mesma área 
do conhecimento e entre as diferentes áreas que organizam a Educação Básica, no contexto da BNCC" (BRASIL, 2016, p. 47). Os temas são: Economia, educação financeira e sustentabilidade; Culturas indígenas e africanas; Culturas digitais e computação; Direitos humanos e cidadania; e Educação ambiental. "Esses temas derivam de um ordenamento legal que implica em alterações nas orientações curriculares emanadas da LDB ou que agregam responsabilidades aos sistemas de ensino em relação a temáticas a serem abordadas no currículo" (BRASIL, 2016, p. 48). Ainda destacam que:

O Tema Especial economia, educação financeira e sustentabilidade, contribui para que a escola assuma a responsabilidade de formar cidadãos conscientes e comprometidos com a construção de relações mais sustentáveis dos sujeitos entre si e com o planeta. Esse tema relaciona-se, ainda, à Estratégia Nacional de Educação Financeira instituída por meio do Decreto $\mathrm{n}$ o 7.397/2010, cujo objetivo é contribuir para o fortalecimento da cidadania ao fornecer e apoiar iniciativas que ajudem a população a tomar decisões financeiras mais autônomas e conscientes. (BRASIL, 2016, p. 49)

De acordo com a Lei de Diretrizes e Bases da Educação Nacional (LDB), Lei no 9394, de 20 de dezembro de 1996, "A educação básica tem por finalidade desenvolver o educando, assegurar-Ihe a formação comum indispensável para o exercício da cidadania e fornecer-lhe meios para progredir no trabalho e em estudos posteriores" (BRASIL, 2005, p. 14). Já no ensino médio, sendo a etapa final da educação básica, o documento apresenta quatro finalidades, sendo que uma delas é "a preparação básica para o trabalho e a cidadania do educando para continuar aprendendo, de modo a ser capaz de se adaptar com flexibilidade a novas condições de ocupação ou aperfeiçoamento posteriores" (BRASIL, 2005, p. 18). Sabe-se que para o exercício da cidadania os estudantes devem ser preparados para, em sua vida cotidiana, tomar decisões responsáveis, tanto na sua vida profissional, como pessoal.

Conforme destacam Godfrey e Edwards (2007, p. 170), quando o estudante aprende sobre dinheiro, ele aprende sobre valores, e um desses valores é a cidadania. As autoras trazem um questionamento muito interessante que, segundo elas, os pais devem sempre se perguntar: "O que devo dizer ao meu filho sobre finanças que eu gostaria que alguém tivesse me dito quando eu tinha a idade dele?". As autoras também apontam que as escolas e as empresas, aos poucos, estão percebendo que a Educação Financeira é importante, e que as crianças de hoje não tem conhecimento suficiente sobre dinheiro, e por esse motivo é importante introduzir Educação Financeira na vida das pessoas desde cedo.

Em relação a importância da Educação Financeira, o mundo mudou, e muitos jovens possuem cartão de crédito, porém, não foram educados sobre investimentos, finanças, economia e impostos, ou seja, muitos jovens estão despreparados diante do mundo consumista. Já as pessoas alfabetizadas financeiramente sabem lidar com o seu dinheiro, como também sabem gastar, ganhar, poupar e também investir. A Educação Financeira é um instrumento capaz de proporcionar às pessoas melhor bem-estar, e melhor qualidade de vida (PERETTI, 2008). Segundo Pietras (2014, p. 20):

Geralmente, as pessoas acabam apelando para o crediário porque não possuem recursos suficientes para pagar pelo produto à vista e não conseguem lidar com a ansiedade de consumir naquele momento. Vão às lojas, compram o que desejam e dividem o valor total em parcelas que seus 
salários podem pagar. E assim começa uma grande roda viciosa, porque aquele dinheiro que a pessoa poderia guardar mensalmente é destinado para o pagamento das dívidas e quando ela sentir novamente a necessidade de consumo, não terá dinheiro para fazê-lo à vista, desfrutando dos descontos, e terá que fazer novas prestações e pagar novos juros, ou seja, trabalhar para pagar suas contas.

A abertura econômica a partir de 1990 e a estabilização da moeda em 1994 contribuíram para a redução da inflação, fazendo com que as pessoas tivessem uma nova visão sobre a gestão financeira, favorecendo para um processo de mudança cultural e um novo aprendizado. O resultado dessa mudança foi o aumento do poder aquisitivo, do crédito e também o alongamento dos prazos de financiamentos, como também o aumento do consumo, da poupança e do investimento. Com esse cenário de grandes mudanças em um pequeno espaço de tempo é muito importante dar atenção sobre como as pessoas estão interagindo com elas, pois estas questões estão ligadas a problemas como a inadimplência, o endividamento familiar e a falta de capacidade das pessoas em se planejar em longo prazo, e também na qualidade das decisões particulares que pode acabar influenciando toda a economia (VIEIRA; BATAGLIA; SEREIA, 2011).

Neste sentido, a Educação Financeira na escola pode ajudar os estudantes a refletirem sobre essas práticas financeiras, auxiliando na tomada de decisões em diversas situações do cotidiano, bem como o conhecimento da diferença paga quando decidimos comprar algum produto à vista ou no crediário, e quais as vantagens de cada opção de pagamento. Como a Educação Financeira está ligada a autonomia e a formação do cidadão, a partir do momento que ela é ensinada para o estudante em sala aula, o professor está construindo um saber que auxiliará o estudante para diversas situações relacionadas ao seu dia a dia, bem como a construção de sua autonomia.

Pressupõe-se que uma população financeiramente educada tende a ser bem informada e ciente do funcionamento dos mecanismos econômicos e, consequentemente, tende a tomar decisões financeiras planejadas, tende a estar menos exposta a riscos financeiros, tende a reduzir a vulnerabilidade do sistema previdenciário e, principalmente, do sistema financeiro. Assim, políticas educativas tornam-se complementares a medidas de regulação financeira na promoção da estabilidade financeira internacional, mobilizando, no âmbito dos governos federais, instituições financeiras e educacionais, às quais, em conjunto, cabe promover a educação financeira da população. É nesse contexto que a consolidação da educação financeira como estratégia nacional de caráter educacional tende a se refletir na redefinição dos espaços atualmente ocupados pelos conteúdos já consolidados no currículo escolar dos países que passaram a considerá-la nacionalmente necessária. (HOFMANN, 2013, p. 3)

Assim, educando desde cedo as crianças e os jovens com situações financeiras úteis para o seu dia a dia e implementando a Educação Financeira nas escolas, pode-se tornar as crianças e os jovens estudantes em pessoas e cidadãos mais preparados não somente para o momento presente, mas sim para o futuro. Hofmann $(2013$, p. 27) ressalta os jovens, por estarem mais expostos do que os seus próprios pais as mudanças no mercado de trabalho e também nos sistemas previdenciários, "[...] seriam um público alvo particularmente relevante para a disseminação da educação financeira [...] Além disso, muitos jovens se defrontam com a necessidade de tomar decisões com impacto ao longo de toda a vida, como escolha profissional". Nesse sentido, a autora conclui que seria importante educar 
os jovens mediante promoção do letramento financeiro antes que eles tomassem parte em contratos e transações financeiros com um alto valor.

\section{METODOLOGIA}

A pesquisa desenvolvida com os estudantes seguiu os princípios da investigação qualitativa, que segundo Bogdan e Biklen (1994), apresenta muitas formas e é conduzida em vários contextos. Neste trabalho, "os dados recolhidos são designados por qualitativos, o que significa ricos em pormenores descritivos relativamente a pessoas, locais e conversas [...]" (BOGDAN; BIKLEN, 1994, p. 16).

Segundo Bogdan e Biklen (1994), neste trabalho não foi usado questionários, pois o caráter reflexivo dessa investigação é permitir que os sujeitos respondam a partir da sua perspectiva pessoal, ou seja, não se moldarem a questões que já foram previamente elaboradas. Para que os sujeitos da pesquisa pudessem se expressar livremente sobre suas opiniões sobre determinados assuntos, a pessoa do próprio investigador é o único instrumento. Assim, a investigadora enfocou mais pelo processo do que pelos resultados, e os dados são descritivos e coletados pela investigadora no local de estudo, a sala de aula, que é o ambiente natural, em contato direto com a investigadora.

Os sujeitos da pesquisa foram 26 estudantes de uma turma do oitavo ano dos anos finais do ensino fundamental de uma escola que é localizada na cidade de Blumenau - SC. Um conjunto de atividades foram elaboradas pela pesquisadora, sendo que os dados das atividades referem-se ao ano de 2016. A aplicação das atividades aconteceram durante 3 aulas de Matemática.

\section{DESCRIÇÃO DAS ATIVIDADES PEDAGÓGICAS}

Antes de iniciar a aplicação das atividades, a pesquisadora discutiu com os estudantes a importância da Educação Financeira no ambiente escolar e familiar, o problema do consumismo e o quanto o consumo exagerado de mercadorias compromete o nosso meio ambiente, o crescimento do endividamento da população, suas causas e consequências, e o panorama brasileiro econômico e financeiro atualmente.

Após a explicação do tema, a primeira atividade proposta para os estudantes foi a seguinte: Segundo uma pesquisa realizada pelo Serviço de Proteção ao Crédito (SPC Brasil) e pela Confederação Nacional de Dirigentes Lojistas (CNDL) com 600 pessoas de ambos os sexos e acima de 18 anos de idade, de todas as regiões brasileiras e de todas as classes sociais, a principal meta da população brasileira para o ano de 2016 é "sair do vermelho". Entre as 600 pessoas, 36,8\% desejam pagar suas contas atrasadas.

a) Explique o que significa "sair do vermelho".

b) Com base nos dados oferecidos, quantas pessoas desejam pagar as suas dívidas? 
Com esta atividade, espera-se que os estudantes conheçam o que é o Serviço de Proteção ao Crédito (SPC Brasil) e também a Confederação Nacional de Dirigentes Lojistas (CNDL). Nessa primeira atividade também espera-se revisar alguns conteúdos como porcentagem, regra de três e arredondamento.

É importante explicar para os estudantes que o Serviço de Proteção ao Crédito (SPC Brasil) é um sistema de informações das Câmaras de Dirigentes Lojistas - CDL que auxilia na tomada de decisões para concessão de crédito pelas empresas em todo país, e tem como objetivo contribuir para o desenvolvimento do mercado de consumo. O SPC Brasil é o mais completo banco de dados da América Latina que possui informações creditícias sobre pessoas físicas e também jurídicas. Já a Confederação Nacional de Dirigentes Lojistas (CNDL) é representante do varejo brasileiro, ou seja, uma entidade que representa o comércio lojista.

Primeiramente, a pesquisadora leu e explicou toda a questão, destacando o que significava o SPC Brasil e o CNDL. Nenhum estudante conhecia o significado dessas siglas, mas alguns relataram que já ouviram falar sobre o SPC. Após a explicação da questão, todos os estudantes receberam uma calculadora, porém foi destacado que era necessário apresentar todos os cálculos realizados nas atividades.

$\mathrm{Na}$ letra a os estudantes opinaram sobre o que significa "sair do vermelho". Todos conseguiram responder a essa pergunta e apresentaram respostas de uma maneira muito semelhante, destacando que "sair do vermelho" é conseguir pagar as suas contas que estão atrasadas ou acabar com suas dívidas, como pode-se ver na Figura 1:

Figura 1 - Resposta de um estudante sobre o que significa sair do vermelho.

a) Explique o que significa "sair do vermelho".

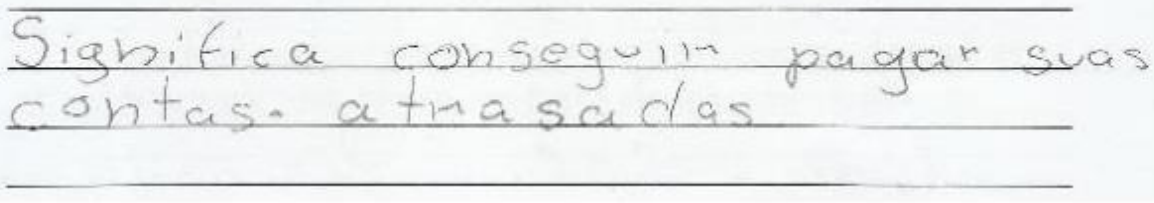

(Fonte: Acervo da pesquisa, 2016)

Outras respostas apresentadas pelos estudantes para essa questão foram: "Sair da pobreza, conseguir pagar suas dívidas e suas contas com seu próprio dinheiro sem se afundar mais" (Estudante A). "Sair de uma situação financeira ruim" (Estudante B). "Que desejam pôr suas contas em dia, enfim, pagar elas e sair do aperto" (Estudante C).

A pesquisadora refletiu com os estudantes sobre os motivos dessas pessoas estarem "no vermelho" e sobre as possíveis atitudes que essas pessoas poderiam ter tomado para evitar que chegassem nessa situação. Segundo a Conef (2013), um dos objetivos da Educação Financeira é ensinar a planejar em curto, médio e longo prazos. "A Educação Financeira intenciona conectar os distintos tempos, conferindo às ações do presente uma responsabilidade pelas consequências do 
futuro" (CONEF, 2013, p. 5). Também é importante destacar para os estudantes que, quando uma pessoa "está no vermelho" nem sempre foi pelo motivo de que a pessoa não controlou os seus gastos, pois imprevistos também acontecem. Para Conef (2013, p. 5) outro objetivo da Educação Financeira é desenvolver a cultura da prevenção.

[...] é prudente planejar pensando nas intempéries da vida. Ninguém está isento de enfrentar situações adversas e inesperadas que podem demandar o uso de uma quantia de dinheiro não prevista no orçamento. Para garantir maior tranquilidade diante de tais situações, há de se conhecer o leque de opções disponíveis, tais como: evitar desperdícios, guardar dinheiro, fazer seguros diversos ou investimentos ou dispor de planos de previdência (pública ou privada).

Já na letra $b$ da questão, alguns estudantes apresentaram dificuldade para entender como realizar o cálculo. Por esse motivo, a pesquisadora relembrou como utilizar a regra de três, e fez um exemplo no quadro. No decorrer da atividade, um estudante questionou sobre como arredondar um valor, e nesse momento a pesquisadora explicou: Queremos saber a quantidade de pessoas. Realizei os cálculos e minha resposta final foi 252,3 . Nesse caso arredondamos 252,3 para aproximadamente 252 pessoas. 0 mesmo estudante então questionou: E se for 252,5 pessoas? Então são 252 ou 253 pessoas? A pesquisadora explicou que, nesse caso, são aproximadamente 252 pessoas.

Dos 26 estudantes, 19 conseguiram realizar todos os passos dessa questão e chegar na resposta correta, que são aproximadamente 221 pessoas. 0 restante não conseguiu realizar a regra de três corretamente.

Figura 2 - Estudante realizando as atividades propostas pela pesquisadora.

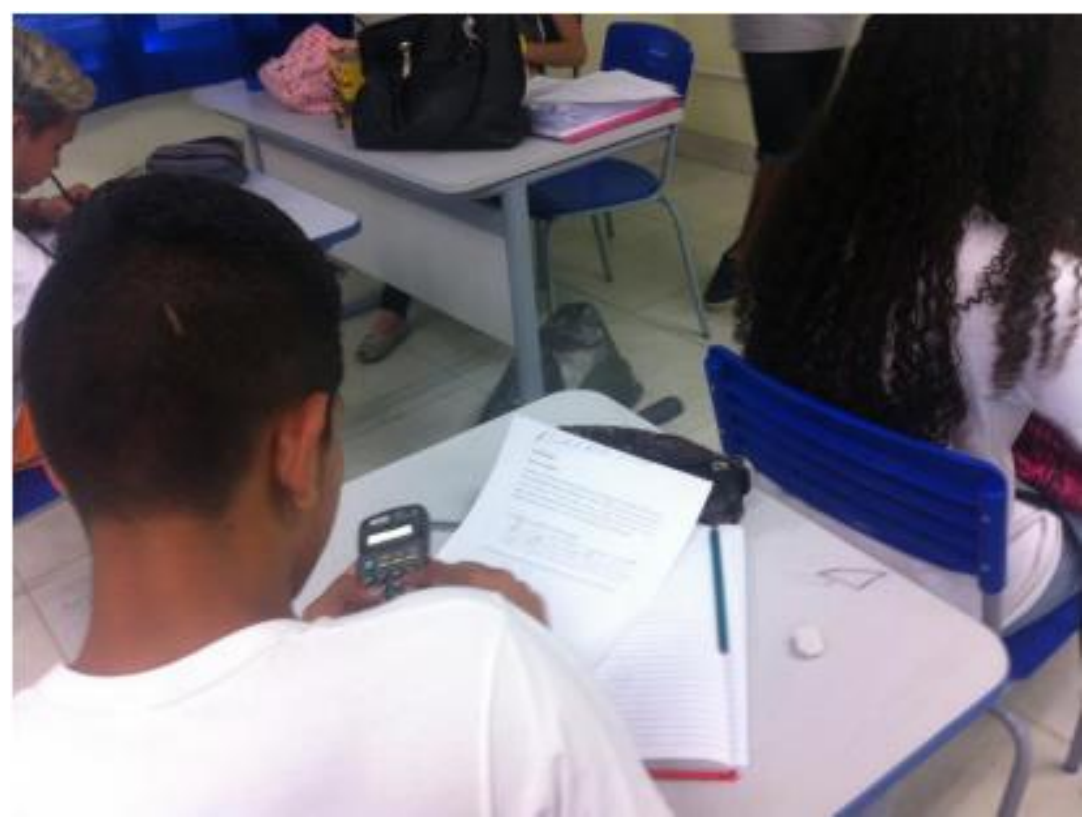

(Fonte: Acervo da pesquisa, 2016) 
Outra atividade proposta aos estudantes tratava-se de uma atividade sobre os gastos da sua família no mercado. Uma semana antes da realização das atividades, a professora de Matemática da turma solicitou aos estudantes que trouxessem um cupom fiscal de uma compra no mercado da sua família. A atividade proposta foi a seguinte:

Visto os gastos excessivos durante o ano de 2015, a família de Carolina chegou à conclusão que está gastando muito com as compras no mercado. Para iniciar o ano de 2016 com os gastos menores, decidiram fazer a compra do mês de janeiro e guardar o cupom fiscal. Com esse cupom, Carolina separou os produtos comprados em: gastos necessários e gastos supérfluos (desnecessários). A compra do mês de janeiro da família de Carolina foi de $R \$ 620,55$, sendo que $R \$ 164,30$ foram gastos supérfluos.

Após a leitura e explicação da questão, os estudantes responderam a primeira pergunta: a) E na sua casa, alguém controla os gastos do mercado? Se sua resposta for sim, quem é essa pessoa? Espera-se que os estudantes que não sabem responder essa pergunta questionem em casa com a sua família se alguém controla os gastos no mercado. Continuando a atividade, com o cupom fiscal, os estudantes completaram o quadro abaixo:

\begin{tabular}{|l|l|l|}
\hline Total da compra & Total dos gastos necessários & Total dos gastos supérfluos \\
\hline R\$ & R\$ & R\$ \\
\hline
\end{tabular}

Após a soma dos gastos necessários e gastos supérfluos, os estudantes responderam o que concluíram com os gastos no mercado da sua família, e qual a porcentagem dos gastos necessários e dos gastos supérfluos nessa compra. Todos os estudantes conseguiram realizar a atividade, porém, nem todos trouxeram um cupom fiscal de uma compra, por esse motivo alguns utilizaram o cupom fiscal de outro estudante da turma.

Alguns destacaram que ninguém na sua família controla os gastos, enquanto que, nas famílias que controlam os gastos no mercado, 6 estudantes responderam que seu pai controla os gastos, enquanto 12 responderam que são as mães que fazem esse trabalho, 4 o pai e a mãe juntos, e 1 estudante destacou que a avó controla os gastos.

Durante a realização da atividade, um estudante solicitou ajuda para a pesquisadora pois estava com dúvidas: "A minha compra deu $R \$ 465,51$ e não tem nada de supérfluo. O que eu faço?". A pesquisadora explicou que então, nessa compra, todos os gastos foram necessários. Na primeira pergunta, o estudante destacou que seu pai controla os gastos no mercado. Na segunda, o estudante completou o quadro com o total da compra, os gastos necessários e supérfluos, como pode-se ver na Figura 3:

Figura 3 - Resposta de um estudante sobre os gastos no mercado.

\begin{tabular}{|l|l|l|}
\hline Total da compra & \multicolumn{1}{|l|}{ Total dos gastos necessários } & \multicolumn{2}{|l|}{ Total dos gastos supérfluos } \\
\hline $\mathrm{R} \$ 465,51$ & $\mathrm{R} \$ \quad 465,51$ & $\mathrm{R} \$ \mathrm{O}$ \\
\hline
\end{tabular}


Na terceira pergunta, onde os estudantes apresentavam sua opinião sobre o que concluíram com os gastos dessa compra no mercado, esse mesmo estudante concluiu que: "Que tudo que gastamos nada é supérfluo e isso é muito bom". Já na última questão, os estudantes deveriam calcular a porcentagem de gastos necessários e de gastos supérfluos. O estudante então apresentou:

Figura 4 - Resposta de um estudante sobre os gastos no mercado.

c) Qual a porcentagem dos gastos necessários e dos gastos supérfluos?

$$
\begin{gathered}
100 \% \text { hecessárias } \\
0 \% \text { supér fluos }
\end{gathered}
$$

(Fonte: Acervo da pesquisa, 2016).

Um outro estudante solicitou a ajuda da pesquisadora pois queria saber a sua opinião sobre a sua resposta na letra $b$, onde os estudantes devem escrever o que concluem com os gastos em mercado da sua família. A compra da família resultou em $\mathrm{R} \$ 160,90$. O estudante concluiu que $\mathrm{R} \$ 100,90$ foram de gastos necessários e o restante de gastos supérfluos. Então na resposta da letra b ele destacou: "Que 60 reais é pra mim". A pesquisadora pediu que o estudante explicasse a sua resposta, então ele disse: "Eu acho que as coisas supérfluas que meus pais compram no mercado são coisas pra mim, tipo bolacha, salgadinho essas coisas".

Figura 5 - Estudante realizando a atividade sobre gastos no mercado.

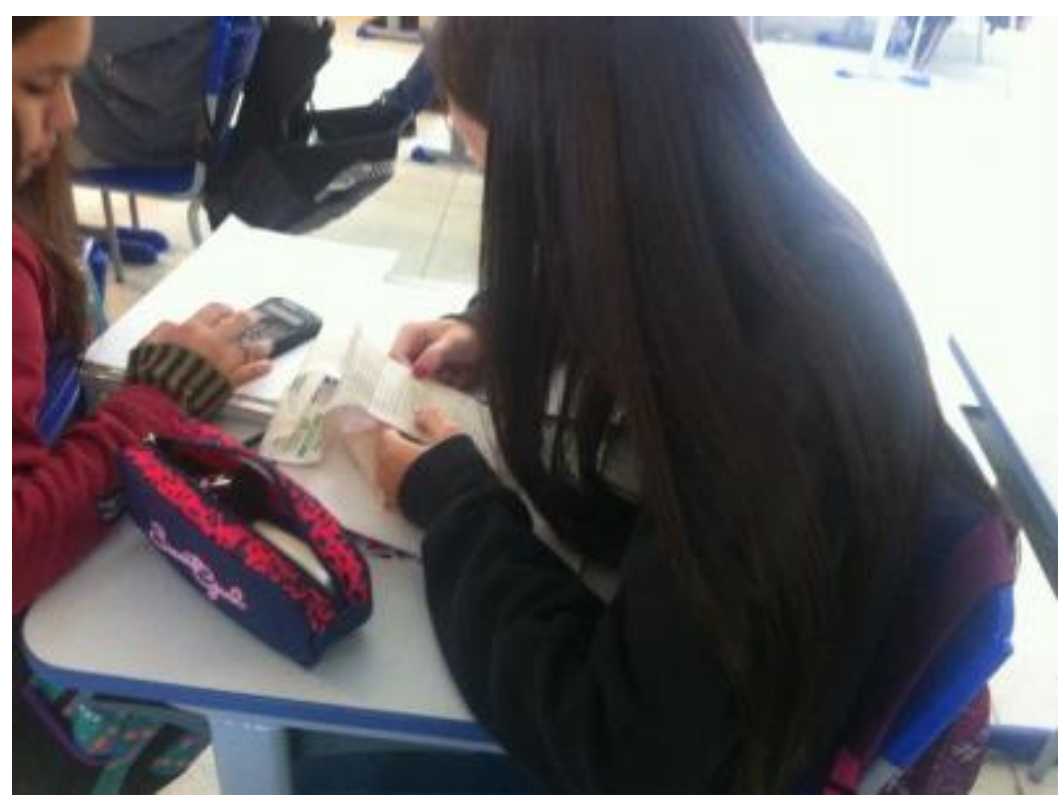

(Fonte: Acervo da pesquisa, 2016) 
Como a professora de Matemática da turma explicou que não precisava ser um cupom fiscal de uma compra grande ou com um valor alto, alguns estudantes trouxeram de compras com um valor pequeno. Um estudante tinha em mãos um cupom fiscal de uma compra no valor total de $R \$ 27,96$. O estudante concluiu que apenas $R \$ 7,98$ foram gastos necessários, e o restante, $R \$ 19,98$, foram gastos supérfluos. Logo, ele apresentou à seguinte conclusão sobre os gastos da sua família nessa compra: "Que eles gastam muito dinheiro com o que não precisa". Todos os estudantes conseguiram realizar a atividade e responder a pergunta que questionava a sua conclusão sobre os gastos no mercado da sua família.

Outras respostas apresentadas pelos estudantes foram: "Concluí que temos mais gastos necessários do que supérfluos, mas mesmo assim teria como evitar um pouco mais os gastos supérfluos" (Estudante A). "Concluí que compramos mais o que é necessário do que supérfluo, e isso é bom" (Estudante B). Já na última questão dessa atividade, onde os estudantes deveriam calcular a porcentagem dos gastos necessários e dos gastos supérfluos nessa compra, apenas 11 dos 26 estudantes conseguiram realizar os cálculos e obter a porcentagem dos gastos necessários e supérfluos corretamente.

\section{CONSIDERAÇÕES FINAIS}

Este trabalho teve como finalidade relatar duas atividades aplicadas com estudantes de uma turma dos anos finais do ensino fundamental e descrever a importância da Educação Financeira no mundo escolar e na vida das pessoas, refletindo sobre o cenário atual financeiro da população brasileira e o problema do consumismo. Nos dias de hoje ouve-se com muita frequência nas mídias sobre o endividamento da população e o crescimento do número de pessoas endividadas. Por esse motivo, acredita-se que a Educação Financeira deve ser implementada na educação básica desde as séries iniciais, para que assim os estudantes possam aprender a lidarem com situações financeiras desde cedo.

Com base nos resultados obtidos após a explicação do conteúdo e da aplicação das atividades, constatou-se que a maioria dos estudantes compreendem os conceitos e a importância da Educação Financeira no mundo escolar e no seu dia a dia. Durante a realização das atividades percebeu-se também que alguns estudantes possuem dificuldade em realizar cálculos como a regra de três, e também arredondamento de números, o que dificulta a compreensão das questões propostas. Por fim, pode-se concluir que o interesse dos estudantes pelo tema Educação Financeira ajudou a pesquisadora a instigar os estudantes a refletirem sobre suas práticas financeiras no dia a dia, como também na resolução das atividades propostas pela pesquisadora.

É importante aprender Educação Financeira nas escolas, pois uma pessoa educada financeiramente desde cedo pode tomar melhores decisões no campo econômico e financeiro, e tornar-se um cidadão com consumos conscientes e uma vida financeira mais responsáve 


\title{
FINANCIAL EDUCATION WITH REAL DATA: DIDACTIC ACTIVITIES FOR BASIC EDUCATION
}

\begin{abstract}
This paper presents a part of a research conducted during the Post-Graduation Program in Teaching Natural Sciences and Mathematics from Universidade Regional de Blumenau. This paper aims to develop and apply didactic activities for basic education concerning financial education based on real data and it also helps to prepare the students for a sustainable consuming and for a responsable financial life. The research subjects were 26 students from the final years of highschool from a public school located in Blumenau/SC. Financial education can contribute to the process of the construction of citizenship, give the students autonomy and prepare them to make better decisions on the economic and financial fields. This paper also presents 2 activities developed with the students during Math classes.
\end{abstract}

KEYWORDS: Financial education. Highschool. Activities. 


\section{Agradecimentos}

À Universidade Regional de Blumenau - FURB pelo convênio de gratuidade do mestrado. À equipe pedagógica juntamente com a professora de Matemática da escola localizada em Blumenau-SC, pelo apoio e incentivo durante a realização das atividades.

\section{REFERÊNCIAS}

BOGDAN, R. C.; BIKLEN, S. K. Investigação qualitativa em educação: uma introdução a teoria e aos métodos. Porto: Porto Ed., 1994.

BRASIL. Base Nacional Comum Curricular. Proposta preliminar. 2a versão revista. 2016.

BRASIL. Lei de Diretrizes e Bases da Educação Nacional. Brasília, DF, 2005.

BRASIL, MINISTÉRIO DE EDUCAÇÃO E CULTURA. Parâmetros Curriculares Nacionais: matemática / Secretaria de Educação Fundamental. Brasília: MEC/ SEF, 1998.

CAMPOS, M. C. Educação financeira na matemática do ensino fundamental: uma análise da produção de significados. 2012. 179f. Dissertação (Mestrado Profissional em Educação Matemática) - Universidade Federal de Juiz de Fora, Juiz de Fora, 2012.

CONEF. Educação financeira nas escolas: ensino médio: livro do professor. Brasília: CONEF, 2013.

DELORS, J. et al. Educação: um tesouro a descobrir - Relatório para a UNESCO da Comissão Internacional sobre Educação para o Séc. XXI. 4 ed. São Paulo: Cortez; Brasília, DF: MEC: UNESCO, 2000.

DOMINGOS, R. Terapia financeira: realize seus sonhos com educação financeira. São Paulo: DSOP Educação Financeira, 2011.

GODFREY, N. S.; EDWARDS, C. Dinheiro não dá em árvore: um guia para os pais criarem filhos financeiramente responsáveis. Tradução de Elizabeth Arantes Bueno. São Paulo: Jardim dos Livros, 2007.

HOFMANN, R. M. Educação financeira no currículo escolar: uma análise comparativa das iniciativas da Inglaterra e da França. Tese (Doutorado em Educação) - Setor de Educação da Universidade Federal do Paraná, Curitiba, 2013. 
PELICIOLI, A. F. A relevância da educação financeira na formação de jovens. 2011. 131 f. Dissertação (Mestrado em Educação em Ciências e Matemática) Pontifícia Universidade Católica do Rio Grande do Sul, Porto Alegre, 2011.

PERETTI, L. C. Educação financeira: aprenda a cuidar do seu dinheiro. 3. ed. Dois Vizinhos, PR: Impressul, 2008.

PIETRAS, G. Uma abordagem sobre matemática financeira e educação financeira no ensino médio. 2014. 104 f. Dissertação (Mestrado Profissional em Matemática) - Universidade Estadual de Ponta Grossa, Ponta Grossa, 2014.

SAVOIA, J. R. F.; SAITO, A. T.; SANTANA, F. A. Paradigmas da educação financeira no Brasil. Revista de Administração Pública (RAP), Rio de Janeiro, v. 41, n. 6, p. 1121-1141, 2007.

SPC Brasil. 36\% dos consumidores fazem compras para aliviar o estresse, aponta pesquisa do SPC Brasil. Disponível em:

<https://www.spcbrasil.org.br/imprensa/noticia/1177>. Acesso em: 16 jun. 2016

SPC Brasil. Principal meta dos brasileiros para 2016 é sair do vermelho, mostra SPC Brasil. Disponível em: <

https://www.spcbrasil.org.br/imprensa/noticia/1129>. Acesso em: 16 jun. 2016.

VIEIRA, S. F. A.; BATAGLIA, R. T. M.; SEREIA, V. J. Educação financeira e decisões de consumo, investimento e poupança: uma análise dos alunos de uma universidade pública do norte do Paraná. Revista de Administração da UNIMEP, v.9, n.3, p. 61-86, 2011. 
DOI: $10.3895 /$ rbect.v10n1.5686

Como citar: GADOTTI, A. C.; BAIER, T. Educação financeira por meio de dados reais: atividades didáticas para a educação básica. Revista Brasileira de Ensino de Ciência e Tecnologia, v. 10, n. 1, 2017. Disponível em: <https://revistas.utfpr.edu.br/rbect/article/view/5686>. Acesso em: xxx

Direito autoral: Este artigo está licenciado sob os termos da Licença Creative Commons-Atribuição 4.0

Internacional. 